\title{
Stronger feelings of loneliness among Moroccan and Turkish older adults in the Netherlands: in search for an explanation
}

\author{
Theo G. van Tilburg ${ }^{1}\left[\right.$ [ $\cdot$ Tineke Fokkema ${ }^{2,3,4}$ (1)
}

Published online: 22 February 2020

(c) The Author(s) 2020

\begin{abstract}
The prevalence of loneliness among Turkish-Dutch and Moroccan-Dutch older adults is higher than among Dutch older adults of non-migrant origin. Three explanations may account for this difference: (1) differential item functioning might result in scores that vary in intensity and in meaning across categories; (2) the position of migrants is much more vulnerable than that of non-migrants; (3) the lack of protective factors has more severe consequences for older migrants. The Longitudinal Aging Study Amsterdam interviewed 176 persons born in Morocco and 235 born in Turkey, aged 55-66 and living in urban areas. They are compared with a matched sample of 292 Dutch persons. The psychometric properties of the loneliness scale are satisfying, although there is some differential item functioning. Older migrants have more frequent social contacts but are at a disadvantage in other domains. Taking into account differences in social participation, satisfaction with income, mastery and depressive symptoms, the difference between older migrants' and non-migrants' loneliness is reduced by more than half. Protective factors are equally important for older migrants and non-migrants. Exceptions are marriage (less protective for Moroccans), frequent contact with children/children-in-law (mostly for Turks), a higher educational level (protects Moroccans and Turks) and better physical functioning (less for Turks). Being an older migrant and belonging to a minority might further contribute to feelings of loneliness. Interventions can be directed at stimulating social contact, but also at aspects like enhancing the appreciation of their social status and avoiding negative interpretations of a situation.
\end{abstract}

Keywords Loneliness $\cdot$ Older migrants $\cdot$ Measurement equivalence $\cdot$ Risk factors

Responsible editor: Marja J. Aartsen.

Guest editors: Ruxandra Oana Ciobanu and Tineke Fokkema.

This paper is an extension of: Van Tilburg, T. G., \& Fokkema, T. (2018). Hogere eenzaamheid onder Marokkaanse en Turkse ouderen in Nederland: Op zoek naar een verklaring. Tijdschrift voor Gerontologie en Geriatrie, 49, 263-273. https://doi. org/10.1007/s12439-018-0269-1.

Electronic supplementary material The online version of this article (https://doi.org/10.1007/s10433-020-00562-x) contains supplementary material, which is available to authorized users.

Theo G. van Tilburg

Theo.van.Tilburg@vu.nl

1 Department of Sociology, Vrije Universiteit Amsterdam, Amsterdam, The Netherlands

2 Netherlands Interdisciplinary Demographic Institute, The Hague, The Netherlands

3 University of Groningen, Groningen, The Netherlands

4 Department of Public Administration and Sociology, Erasmus University Rotterdam, Rotterdam, The Netherlands

\section{Introduction}

Compared to people without a migration background, loneliness among migrants is common (Ajrouch 2008; Fokkema and Naderi 2013; Vancluysen and Van Craen 2011). Prevalence among migrants varies depending on their origin. In England, the prevalence is high among older adults from Pakistan, Bangladesh, China, Africa and the Caribbean, but not among those of Indian origin (Victor et al. 2012). In Canada, loneliness among older migrants from a different linguistic and cultural background is above average, in contrast to migrants who have many similarities with Canadian-born older adults (de Jong Gierveld et al. 2015). Older migrants in Canada are more lonely, but not when they identify themselves as British or French (Wu and Penning 2015).

Twenty years ago, there were already signs of strong loneliness among older migrants in the Netherlands, but the image of isolation and loneliness was considered as a possible cliché, fed by harrowing individual cases (Tesser et al. 1998). However, data since 2010 show relatively high levels 
of loneliness among older migrants in the four big Dutch cities (Amsterdam, Rotterdam, The Hague and Utrecht) (el Fakiri and Bouwman-Notenboom 2015; Uysal-Bozkir et al. 2017). Older migrants of Turkish origin are particularly lonely, followed by those of Moroccan and Surinamese origin. The factors related to these differences have not yet been investigated in detail.

In this study, we examine whether differences in loneliness between people aged 55-66 of Moroccan, Turkish and Dutch origin can be understood based on three factors: in comparison with non-migrants, migrants (1) have a different understanding of the concept of loneliness and report loneliness relatively quickly; (2) have higher loneliness-related risks; and (3) suffer more severe consequences when protective factors are lacking. For the sake of conciseness and readability, we mostly refer to the categories of origin as Moroccan, Turkish and Dutch.

\section{The concept and measurement of loneliness}

Loneliness is a negative feeling in a situation of loss and dissatisfaction with the social network. It is the outcome of a process in which a person weighs up his existing personal relationships against his own wishes and social expectations with regard to relationships. If the network of relationships is too small, or the relationships are of insufficient quality, there is often loneliness (de Jong Gierveld et al. 2018). People have a strong need for social relationships in which they find connection, affection and involvement (Baumeister and Leary 1995). Loneliness is a social and historical way of understanding relationships (Bound Alberti 2018), but the core of loneliness is seen as a universal human experience because the need for social relationships is fundamental (Perlman 2004).

Several psychometric studies show that loneliness is measured equivalently in Western and non-Western countries (Durak and Senol-Durak 2010; Hawkley et al. 2012), in several Western countries (van Tilburg et al. 2004) and European countries (de Jong Gierveld and van Tilburg 2010), and among migrants and non-migrants in the Netherlands (Uysal-Bozkir et al. 2017; Visser and el Fakiri 2016). Qualitative research among Dutch residents of Turkish and Surinamese origin (Torensma 2014) indicates sufficient construct validity, although the concept of emptiness points to a lack of feeling of connection with God among older Turks and a lack of social relationships among older Surinamese. It also seems that older Turks have a lower threshold for agreeing to a loneliness item about friendship (Leung and Bond 1989; Victor et al. 2012). Given the repeatedly found cross-national and cross-cultural equivalence of loneliness, Hypothesis 1 is that loneliness of older migrants and nonmigrants can be compared using an existing measurement instrument.

\section{High risks among migrants}

Many factors increase the risk of loneliness. For example, older adults without a partner, have few persons they maintain frequent contact with, lack paid or voluntary work, do not participate in social activities, or have a low income or poor health are at an increased risk of loneliness (Fokkema et al. 2012; Hansen et al. 2009). Older Moroccan and Turkish migrants have many more risk factors than nonmigrants, but not in all domains (Schellingerhout 2004; Steinbach 2018). That older migrants co-reside with children more often protects. However, because their contacts outside the home are often with relatives, their network is homogeneous. They are often low-skilled and usually have a low income. Many started working at a very young age. Later, in the Netherlands, men mostly did physically heavy work under poor working conditions and were either longterm unemployed or prematurely incapacitated for work. It is common for women to never have worked outside the home, but they tend to be the anchor of usually large families. Partly because of language barriers and cultural differences, older migrants can find it difficult to connect with Dutch society (including regular welfare and care institutions) and to take control of their own lives-i.e. they have low mastery. They report a high proportion of chronic conditions and physical limitations in terms of mobility and personal care, as well as a low level of perceived health. Hypothesis 2 is that the stronger loneliness among older migrants compared to non-migrants is partly attributable to the higher risks among older migrants.

\section{Differential risk and protective effects}

Risk and protective factors may carry a different weight for older migrants than for non-migrants, hence affecting the impact on loneliness. Perhaps the most obvious example is the higher importance that older Moroccan and Turkish migrants attach to the family, in particular their children. This protective factor interacts with the risk factor that they, as members of a minority ethnic group, are more likely to experience discrimination (Pettigrew et al. 1997) and social exclusion (de Tavernier and Draulans 2019). This firstly leads to what is known as minority stress (du Plooy et al. 2019; Meyer 2003); social security within the family may help cope with this stress. Secondly, it results in few inter-ethnic meeting opportunities; a lack of alternative social ties increases the need for close and supportive bonds within the family. Their dependency on the family is further reinforced by the resistance of older Moroccans and Turks to professional care and to their adherence to the filial responsibility expectations that are part of their 
collectivistic culture (Conkova and Lindenberg 2018). One might thus assume that being strongly embedded in the family serves as a buffer against loneliness, especially for older Moroccans and Turks. Conversely, those who do not have good contact with family members are likely to be at a greater risk of loneliness than non-migrants. It remains to be seen whether the impact of lacking other resources (i.e. education, income, mastery, health) on loneliness is stronger for older Moroccans and Turks than for their native peers. Hypothesis 3 is that older migrants are on average lonelier than non-migrants partly because the risk factors and the lack of protective factors weigh more heavily on them.

\section{Method}

\section{Respondents}

The data were from the Longitudinal Aging Study Amsterdam (Huisman et al. 2011). The samples were stratified by gender and taken from municipal population registers. In 2012 and 2013, 1023 men and women born between 1948 and 1957 were interviewed-all residents of Amsterdam, Zwolle, Oss, or six surrounding municipalities. The response rate was 63. Almost all were of Dutch origin. In 2013 and 2014, 209 persons of Moroccan origin and 269 of Turkish origin were interviewed. They were residents of Alkmaar, Almere, Amersfoort, Amsterdam, Breda, Eindhoven, Enschede, Haarlem, Helmond, Hilversum, Nijmegen, Oss, Tilburg, Zaanstad and Zwolle. The response rate was 45.

The interviews were conducted in Dutch, Moroccan-Arabic (Darija), Berber (Tarifit) or Turkish. For various questions, the translations were taken from previous research, such as the loneliness scale (Uysal-Bozkir et al. 2017) and the CES-D depression scale (Spijker et al. 2004). Questions unavailable in Moroccan-Arabic, Berber or Turkish were translated by two professionals using the back translation method.

To harmonise the samples, older adults living independently in urban neighbourhoods; married and cohabiting with their partner or unmarried and without a partner; and born in the Netherlands $(N=292)$, Morocco $(N=176)$ or Turkey $(N=235)$ were selected. On average, the migrants had been in the Netherlands since 1977.

\section{Measuring instruments}

Loneliness was measured using the 11-item scale of De Jong Gierveld (de Jong Gierveld and van Tilburg 1999). An answer 'yes' to six negatively formulated items, an answer 'no' to five positively formulated items, and an answer in the category 'more or less' count as a loneliness point. Scale values are $0-11$. Two direct measurements of loneliness were included to indicate concurrent validity: the statement 'I sometimes feel lonely' with the same answer possibilities as the scale items, and whether the respondents count themselves among the not (1), moderate (2), strong (3) or very strong (4) lonely ones. Table 1 shows the descriptive data.

In addition to gender $(0=$ man, $1=$ woman $)$ and age, categories of independent variables covered five domains: social relationships, socio-economic position, social participation, mastery and health. With regard to social relationships, marital status $(0=$ not married and no partner, $1=$ married), number of persons in the household other than the respondent and a spouse (0-8) and number of children $(0-13)$ were assessed. Contact frequency was asked for five types of relationships (Schellingerhout 2004): children/ children-in-law outside the household, grandchildren outside the household, other family, friends and acquaintances, and neighbours and other people in the neighbourhood. For the last two, Moroccans and Turks answered for Moroccan and Turkish relationships, respectively, and for Dutch and other relationships. Across the two questions, the highest frequency was chosen. Answer options vary from 'less than monthly' (1) to 'every day' (5).

Socio-economic position was measured with three variables. Level of education varies from 'no completed' (1) to 'university' education (9). Monthly net income was measured as euros per month in 24 categories. Income satisfaction ranges from 'dissatisfied' (1) to 'satisfied' (5).

Social participation was measured in three dichotomous variables. People were asked whether they worked, whether they were members of an organisation such as a trade union or a political party, and whether they used the Internet. A fourth, ordinal variable is church or mosque attendance, with values ranging from 'not a member or never attend' (1) to 'weekly or more often' (6).

Mastery is the feeling of being able to control important conditions affecting one's life. We presented five statements (Pearlin and Schooler 1978). An example is: 'I have little control over the things that happen to me'. Answer options vary from 'strongly disagree' (1) to 'strongly agree' (5). Cronbach's alpha was 0.83 for Moroccans, 0.80 for Turks and 0.79 for Dutch. Scale values are 5-25.

Five health variables were studied. Answers to the question of general health range from 'poor' (1) to 'excellent' (5). Chronic diseases are diseases and complaints that last at least three months, or for which people are being treated or monitored by a doctor for a long time. We count the number of diseases (maximum six). Six questions referred to physical activities in daily life, such as walking. Answer options range from 'cannot perform the activity' (1) to 'the activity is performed without help' (5). Cronbach's alpha was 0.77 for Moroccans, 0.87 for Turks and 0.82 for Dutch. Scale values are 6-30. Cognitive functioning was measured using 
Table 1 Descriptive data (mean or proportion) by origin

\begin{tabular}{|c|c|c|c|c|c|c|c|c|c|}
\hline & \multirow{2}{*}{\multicolumn{2}{|c|}{$\frac{\text { Dutch }}{N=292}$}} & \multirow{2}{*}{\multicolumn{2}{|c|}{$\frac{\text { Moroccan }}{N=176}$}} & \multirow{2}{*}{\multicolumn{2}{|c|}{$\frac{\text { Turkish }}{N=235}$}} & \multirow{3}{*}{$\begin{array}{l}\text { Dutch versus } \\
\text { Moroccan }\end{array}$} & \multirow{3}{*}{$\begin{array}{l}\text { Dutch ver- } \\
\text { sus Turkish }\end{array}$} & \multirow{3}{*}{$\begin{array}{l}\text { Moroccan } \\
\text { versus Turk- } \\
\text { ish }\end{array}$} \\
\hline & & & & & & & & & \\
\hline & $\mathrm{M}$ & SD & $\mathrm{M}$ & SD & $\mathrm{M}$ & $\mathrm{SD}$ & & & \\
\hline Loneliness (scale score, $0-11$ ) & 1.7 & 2.6 & 4.5 & 3.1 & 5.6 & 3.3 & $* * *$ & $* * *$ & $* * *$ \\
\hline I sometimes feel lonely (1-3) & 1.5 & 0.7 & 1.7 & 0.9 & 2.0 & 0.9 & $*$ & $* * *$ & $* * *$ \\
\hline I am among the $\ldots$ lonely people (1-4) & 1.2 & 0.5 & 1.6 & 0.8 & 1.9 & 0.7 & $* * *$ & $* * *$ & $* * *$ \\
\hline Female (vs. male) & 0.54 & & 0.39 & & 0.44 & & $* *$ & & \\
\hline Age (55-66) & 60.6 & 3.1 & 60.9 & 2.9 & 60.8 & 3.1 & & & \\
\hline Married (vs. not married and no partner) & 0.70 & & 0.81 & & 0.78 & & $*$ & & \\
\hline Number of persons in household $(0-8)$ & 0.3 & 0.6 & 2.1 & 1.8 & 0.7 & 1.0 & $* * *$ & $* * *$ & $* * *$ \\
\hline Number of children $(0-13)$ & 1.8 & 1.3 & 4.7 & 2.3 & 3.5 & 1.6 & $* * *$ & $* * *$ & $* * *$ \\
\hline Contact frequency with children/children-in-law (1-5) & 3.3 & 1.6 & 3.9 & 1.4 & 4.2 & 1.0 & $* * *$ & $* * *$ & $*$ \\
\hline Contact frequency with grandchildren (1-5) & 2.3 & 1.5 & 3.2 & 1.5 & 3.4 & 1.4 & $* * *$ & $* * *$ & \\
\hline Contact frequency with other kin (1-5) & 3.4 & 0.9 & 2.9 & 1.1 & 2.9 & 1.0 & $* * *$ & $* * *$ & \\
\hline Contact frequency with friends/acquaintances (1-5) & 3.7 & 0.8 & 4.0 & 1.2 & 4.1 & 0.9 & $* *$ & $* * *$ & \\
\hline Contact frequency with neighbours (1-5) & 3.8 & 1.0 & 4.1 & 1.1 & 4.1 & 1.0 & $* *$ & $* *$ & \\
\hline Educational level (1-9) & 5.6 & 2.2 & 2.5 & 2.1 & 2.6 & 1.8 & $* * *$ & $* * *$ & \\
\hline Income level (1-24) & 13.6 & 5.7 & 7.5 & 3.1 & 7.8 & 3.2 & $* * *$ & $* * *$ & \\
\hline Satisfaction with income (1-5) & 4.1 & 1.3 & 2.7 & 1.6 & 2.1 & 1.3 & $* * *$ & $* * *$ & $* * *$ \\
\hline Employed (vs. non-employed) & 0.58 & & 0.30 & & 0.20 & & $* * *$ & $* * *$ & \\
\hline Membership in organisations (vs. no membership) & 0.73 & & 0.77 & & 0.95 & & & $* * *$ & $* * *$ \\
\hline Internet use (vs. no use) & 0.91 & & 0.40 & & 0.32 & & $* * *$ & $* * *$ & \\
\hline Church/mosque attendance (1-6) & 1.8 & 1.4 & 4.7 & 1.9 & 4.3 & 1.9 & $* * *$ & $* * *$ & $*$ \\
\hline Mastery (5-25) & 18.8 & 3.3 & 16.7 & 5.6 & 13.8 & 4.6 & $* * *$ & $* * *$ & $* * *$ \\
\hline General health (1-5) & 3.7 & 0.9 & 2.6 & 1.1 & 2.5 & 1.0 & $* * *$ & $* * *$ & \\
\hline Number of chronic diseases (0-6) & 1.0 & 0.9 & 1.3 & 1.1 & 2.0 & 1.4 & $*$ & $* * *$ & $* * *$ \\
\hline Physical functioning (6-30) & 28.9 & 2.6 & 27.1 & 3.9 & 24.8 & 5.5 & $* * *$ & $* * *$ & $* * *$ \\
\hline Cognitive functioning $(0-30)$ & 28.5 & 1.6 & 27.2 & 2.5 & 26.0 & 2.8 & $* * *$ & $* * *$ & $* * *$ \\
\hline Depressive symptoms (0-60) & 7.7 & 7.3 & 15.9 & 11.3 & 18.2 & 11.0 & $* * *$ & $* * *$ & \\
\hline
\end{tabular}

${ }^{*} p<0.05 ; * * p<0.01 ; * * * p<0.001 ; N=703$

the Mini-Mental State Examination (Folstein et al. 1975), with values between 'very poor' (0) and 'good' (30). Twenty items were presented about depressive symptoms (Radloff 1977). Cronbach's alpha was 0.92 for Moroccans, 0.91 for Turks and 0.90 for Dutch. Scale values are 0-60.

\section{Procedure}

For Hypothesis 1, we investigated psychometric scale characteristics within the three origin categories. Loevinger's homogeneity indicates the correlation between the item scores (lower limit 0.30) (Mokken 1971). Reliability looks at the interrelationship in terms of number of items (lower limit 0.80) (Nunnally and Bernstein 1994). For reliability, we calculated Cronbach's alpha and an improved version of it called the 'greatest lower bound' (GLB) (Bendermacher 2010). There is concurrent validity when a measurement is sufficiently related to other variables that are likely to measure the same concept (de Groot 1961). We calculated the correlation between the scale score and the answers to the two direct loneliness questions (Spearman's rho; from 0.50 the correlation is seen as moderate to strong). Bias ('differential item functioning') was tested by verifying, for each item in the pooled sample, whether the degree of consent given in the origin categories corresponded with the scale score (uniform) and the increasing chance of consent for an increasing scale score (non-uniform) (Osterlind and Everson 2009). Logistic regression of the dichotomised item score was performed with origin and scale score as interacting predictors. The Wald statistic is Chi-square distributed and sensitive to sample size. Predicted values were used to determine item characteristic curves.

By means of variance analysis with the Bonferroni correction, we examined whether risk factors affect migrants more often compared to the Dutch. For testing Hypothesis 2, we applied ordinary linear regression analysis of loneliness 
in SPSS and investigated which factors are associated with loneliness. Tolerance testing indicates that all independent variables qualified for the regression analysis assumption concerning the absence of multicollinearity. We imputed missing values (none for loneliness; $1 \%$ for household size, contact with other kin, satisfaction with income level, church/mosque attendance; $2 \%$ for contact with grandchildren; $10 \%$ for income level; $18 \%$ for cognitive functioning) and created twenty data sets, presenting the pooled estimates. We controlled for gender and age, entering the differences between the origin categories as dummy variables. Three sets of analyses were run, first examining whether levels of risk factors reduce the differences in average loneliness by origin, then looking at the effect of individual variables and at the effects in a multivariate model that included all risk factors.

To test Hypothesis 3, we assessed whether the protective effect of factors differs across categories of origin. We conducted stratified regression analysis in Mplus (Muthén and Muthen 2017) and applied Bayesian multiple imputation with twenty iterations. For ease of interpretation of intercept and effects, all variables are centred within the three categories. The unconstrained model has no constraints on coefficient equality across Dutch, Moroccans and Turks. In the constrained model, all parameters are constrained to be equal. We released the constraints for all predictor variables one by one. From these 23 models, we selected models with better fit than the constrained model. Model improvement was reviewed by the Wald-distributed change in $-2 \log$ likelihood and the decrease in Akaike information criterion (AIC), Bayesian information criterion (BIC) and sample-size adjusted BIC; any decrease points to model improvement. The final model only includes equality constraints for predictor variables whose release did not show model improvement. For the other predictor variables, we tested coefficient equality across Dutch, Moroccans and Turks by calculating the $z$-statistic (Clogg et al. 1995). For a further test of model fit, we used the comparative fit index (CFI), the root mean square error of approximation (RMSEA) and the standardised root mean squared residual (SRMR). CFI $\geq 0.95$, RMSEA $\leq 0.06$ and SRMR $\leq 0.08$ support acceptable model fit (Hu and Bentler 1999).

\section{Results}

\section{Loneliness scale validity}

The homogeneity and reliability of the item set within the origin categories are sufficient (Table 2). The correlation between the loneliness scale and the two direct questions indicates concurrent validity. For most characteristics, the values in the three origin categories were close to each other. The exception is the lower homogeneity among Moroccans. For five items, there was no bias: 'I miss having a really close friend', 'I find my circle of friends and acquaintances too limited', 'There are many people I can trust completely', 'I miss having people around me' and 'I often feel rejected'. There was no significant Wald for either main effect of origin or interaction effect (not in the table). The biggest problem was found in the item 'I miss the pleasure of the company of others'. The predicted chances of agreeing to this item are relatively high for Turks, and to a lesser extent for Moroccans (Fig. 1). For example, with a score of 3 points on the loneliness scale the probability of agreeing is 0.65 for Turks and 0.34 for Moroccans, compared to 0.14 for the Dutch (Table 3). This response tendency is also seen in 'I experience a general sense of emptiness'. Turks and Moroccans scored relatively high in the direction of loneliness (so they often denied the item) on the item 'There is always someone I can talk to about my day-to-day problems'. Moroccans scored relatively high in the direction of loneliness on

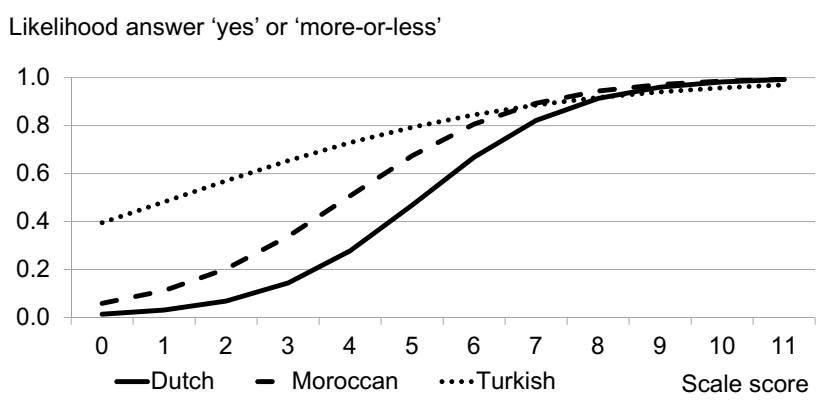

Fig. 1 Item characteristic curve of 'I miss the pleasure of the company of others' by origin
Table 2 Homogeneity, reliability and congruent validity of the loneliness scale by origin

\begin{tabular}{llll}
\hline & Dutch & Moroccan & Turkish \\
\hline Loevinger's homogeneity (H) & 0.48 & 0.30 & 0.44 \\
Reliability (Cronbach's alpha) & 0.87 & 0.80 & 0.84 \\
Reliability (GLB) & 0.92 & 0.87 & 0.89 \\
I sometimes feel lonely (Spearman's rho) & 0.53 & 0.61 & 0.61 \\
I am among the ... lonely people (Spearman's rho) & 0.51 & 0.58 & 0.55 \\
\hline
\end{tabular}

$N=703$ 
Table 3 Bias of loneliness item scores by origin

\begin{tabular}{|c|c|c|c|c|c|c|c|}
\hline & \multicolumn{2}{|l|}{ Uniform } & \multicolumn{2}{|c|}{ Non-uniform } & \multirow{2}{*}{\multicolumn{3}{|c|}{$\begin{array}{l}\text { Likelihood of agreeing when } \\
\text { scale score }=3\end{array}$}} \\
\hline & \multirow{2}{*}{$\begin{array}{l}\text { Moroccan } \\
\text { Wald }\end{array}$} & \multirow{2}{*}{$\begin{array}{l}\text { Turkish } \\
\text { Wald }\end{array}$} & \multirow{2}{*}{$\begin{array}{l}\text { Moroccan } \\
\text { Wald }\end{array}$} & \multirow{2}{*}{$\begin{array}{l}\text { Turkish } \\
\text { Wald }\end{array}$} & & & \\
\hline & & & & & Dutch & Moroccan & Turkish \\
\hline There is always someone I can talk to about my day-to-day problems & $6.8^{* *}$ & $6.0^{*}$ & 3.3 & $7.0 * *$ & 0.18 & 0.30 & 0.25 \\
\hline I miss having a really close friend & 0.0 & 3.3 & 2.8 & 0.7 & 0.29 & 0.19 & 0.42 \\
\hline I experience a general sense of emptiness & 2.7 & $7.7 * *$ & 0.6 & 1.3 & 0.09 & 0.19 & 0.28 \\
\hline There are plenty of people I can lean on when I have problems & $11.1 * * *$ & 0.2 & $7.3^{* *}$ & 0.1 & 0.08 & 0.22 & 0.07 \\
\hline I miss the pleasure of the company of others & $5.3^{*}$ & $47.1 * * *$ & 0.7 & $13.5^{* * *}$ & 0.14 & 0.34 & 0.65 \\
\hline I find my circle of friends and acquaintances too limited & 2.3 & 1.3 & $4.6^{*}$ & $4.0^{*}$ & 0.29 & 0.27 & 0.25 \\
\hline There are many people I can trust completely & 0.6 & 0.1 & $4.4^{*}$ & $4.5^{*}$ & 0.44 & 0.21 & 0.31 \\
\hline There are enough people I feel close to & 2.5 & $4.1^{*}$ & 2.2 & 0.6 & 0.20 & 0.25 & 0.08 \\
\hline I miss having people around me & 2.7 & 0.2 & 2.8 & 1.2 & 0.19 & 0.24 & 0.17 \\
\hline I often feel rejected & 0.0 & 0.1 & 0.1 & 0.0 & 0.05 & 0.05 & 0.04 \\
\hline I can call on my friends whenever I need them & $16.2 * * *$ & 3.4 & $8.0 * *$ & 0.0 & 0.12 & 0.32 & 0.03 \\
\hline
\end{tabular}

${ }^{*} p<0.05 ; * * p<0.01 ; * * * p<0.001 ; N=703$

the items 'I can call on my friends whenever I need them', 'There are enough people I feel close to' (together with the Dutch) and 'There are plenty of people I can lean on when I have problems'. We find support for Hypothesis 1 that the loneliness scale is a valid instrument in this study, yet itemspecific bias should also be considered.

\section{Differences in risk and protective factors}

There were major differences between the three origin categories in the five domains. Moroccans and Turks are more socially embedded than the Dutch, except for contact frequency with other kin (Table 1). Moroccans have more children, persons in the household and contact with children/children-in-law than Turks. Migrants have a relatively weak socio-economic position, with a lower education, lower income and, especially the Turks, less satisfaction with their income than the Dutch. In terms of social participation, migrants are less likely to work and be on the Internet. On the other hand, they attend mosque more often than the Dutch go to church, and more Turks are members of organisations. Migrants, especially Turks, experience less mastery and are in poorer health on all aspects compared to the Dutch.

\section{Explanation of differences in loneliness}

On the basis of the differences in loneliness-related factors, the expectation is that the stronger loneliness among older Moroccan and Turkish migrants cannot be explained by differences in social relationships but by their weaker situation in the four other domains. The results of regression analysis support Hypothesis 2 (Table S1 of the Supplementary
Material). Controlled for age and gender (both not significant), the loneliness of the Dutch is 1.7 points on a scale of $0-11$. The loneliness of Moroccans is 2.8 points higher and that of Turks 3.9 points higher (Model 1). If we take into account the (better) position in the domain of social relationships, the loneliness of Moroccans and Turks is 3.0 and 4.3 points higher, respectively (Model 2). Taking into account differences in socio-economic position, the difference in loneliness is 1.5 and 2.4 points, respectively (Model 3). After adding only variables for social participation, the difference in loneliness is 2.4 and 3.4 points, respectively (Model 4). When we model the differences in mastery, the loneliness of Moroccans and Turks is 2.1 and 2.4 points higher, respectively (Model 5). Finally, controlled for health factors alone, the difference in loneliness is 1.2 and 2.0 points, respectively (Model 6). Each model adjustment is significant $(\mathrm{p}<0.001)$. The weaker socio-economic position, lower social participation and mastery and poorer health thus contribute significantly to the stronger loneliness among Moroccans and Turks. If we include all factors simultaneously in the regression model (Table 4), on average Moroccans are 1.2 points and Turks 1.9 points lonelier than the Dutch. This multivariate model shows that more than half of the difference in loneliness originally found between the origin categories (2.8 for Moroccans and 3.9 points for Turks) can be attributed to differences in the risk factors studied.

The parameters of the regression of loneliness are shown in Table 4. The left-hand section of the table shows the effects, controlled for gender and age, and after entering the differences between the three origin categories. All effects are in the expected direction, and most are statistically significant. The multivariate model in the right-hand 
Table 4 Regression of loneliness (range 0-11)

\begin{tabular}{|c|c|c|c|c|}
\hline & \multicolumn{2}{|c|}{$\begin{array}{l}\text { Controlled for gender, } \\
\text { age, origin }\end{array}$} & \multicolumn{2}{|c|}{ Multivariate } \\
\hline & $\mathrm{B}$ & SE B & $\mathrm{B}$ & SE B \\
\hline Constant & & & 2.80 & $0.20 * * *$ \\
\hline Female (vs. male) & & & -0.45 & $0.20 *$ \\
\hline Age (55-66) & & & 0.04 & 0.03 \\
\hline Moroccan (vs. Dutch) & & & 1.21 & $0.36 * * *$ \\
\hline Turkish (vs. Dutch) & & & 1.87 & $0.32 * * *$ \\
\hline Married (vs. not married and no partner) & -1.98 & $0.25 * * *$ & -1.09 & $0.26^{* * *}$ \\
\hline Number of persons in household $(0-8)$ & -0.10 & 0.10 & 0.04 & 0.09 \\
\hline Number of children $(0-13)$ & -0.12 & 0.07 & 0.03 & 0.07 \\
\hline Contact frequency with children/children-in-law (1-5) & -0.34 & $0.08 * * *$ & -0.16 & 0.08 \\
\hline Contact frequency with grandchildren (1-5) & -0.23 & $0.08 * *$ & -0.10 & 0.08 \\
\hline Contact frequency with other kin (1-5) & -0.35 & $0.11 * *$ & -0.14 & 0.09 \\
\hline Contact frequency with friends/acquaintances $(1-5)$ & -0.58 & $0.11 * * *$ & -0.31 & $0.10^{* *}$ \\
\hline Contact frequency with neighbours $(1-5)$ & -0.45 & $0.11 * * *$ & -0.16 & 0.09 \\
\hline Educational level (1-9) & -0.11 & $0.06^{*}$ & -0.05 & 0.05 \\
\hline Income level (1-24) & -0.18 & $0.03 * * *$ & 0.00 & 0.03 \\
\hline Satisfaction with income (1-5) & -0.61 & $0.08 * * *$ & -0.29 & $0.07 * * *$ \\
\hline Employed (vs. non-employed) & -1.16 & $0.25 * * *$ & -0.07 & 0.23 \\
\hline Membership in organisations (vs. no membership) & -0.50 & 0.30 & -0.04 & 0.25 \\
\hline Internet use (vs. no use) & -0.89 & $0.28 * *$ & 0.24 & 0.25 \\
\hline Church/mosque attendance (1-6) & -0.10 & 0.07 & 0.04 & 0.06 \\
\hline Mastery (5-25) & -0.30 & $0.02 * * *$ & -0.13 & $0.02 * * *$ \\
\hline General health (1-5) & -0.89 & $0.11 * * *$ & -0.08 & 0.11 \\
\hline Number of chronic diseases $(0-6)$ & 0.41 & $0.10 * * *$ & -0.12 & 0.09 \\
\hline Physical functioning (6-30) & -0.18 & $0.03 * * *$ & 0.00 & 0.03 \\
\hline Cognitive functioning $(0-30)$ & -0.09 & 0.06 & 0.03 & 0.05 \\
\hline Depressive symptoms (0-60) & 0.17 & $0.01 * * *$ & 0.11 & $0.01 * * *$ \\
\hline
\end{tabular}

$* p<0.05 ; * * p<0.01 ; * * * p<0.001 . N=703$. Multivariate model: $R^{2}=0.57$ section points to the significance of five factors. Being married reduces feelings of loneliness. Because in the sample migrants are married more often than the Dutch, the average loneliness among Moroccans and Turks is 0.1 points lower. Moroccans and Turks also have more contact with friends and acquaintances, which gives 0.1 points reduction in loneliness. Three factors do increase the average loneliness of migrants: they are more dissatisfied with their income (resulting in an increase in loneliness score of 0.4 points for Moroccans and 0.6 points for Turks), have less mastery ( 0.3 and 0.7 point increase, respectively) and have more depressive symptoms ( 0.9 and 1.2 point increase, respectively).

\section{Difference in protective effects of predictor variables}

Model fit statistics for the prediction of loneliness stratified by origin are presented in Table S2. The unconstrained model has a perfect fit to the data by definition: $\mathrm{CFI}=1.00$, RMSEA $=0.00$ and $S R M R=0.00$. The model with all parameters constrained to be equal across the three categories has good fit to the data. Releasing the effects one by one from the constraint to be equal, we find model improvement for five predictors. The final model shows an improved fit over the constrained model: Wald $=2 *$ - $(1526.1-154$ $6.4)=40.5(\mathrm{df}=10, p<0.001)$, and AIC and sample-size adjusted $\mathrm{BIC}$ are lower. $\mathrm{CFI}=1.00, \mathrm{RMSEA}=0.00$ and $\mathrm{SRMR}=0.01$.

The effects of predictor variables on loneliness variation among Dutch, Moroccans and Turks are presented in Table 5. The results from the tests of coefficient equality (Hypothesis 3) show differences for four predictor variables only (the differences between the intercepts reflect differences in the means across origin categories). Marriage protects the Dutch more than Moroccans. Controlled for the other predictors, married Dutch are estimated to have a loneliness score 1.2 and non-married Dutch 2.8-a difference of 1.6 points. The difference is much smaller among Moroccans ( 0.4 points, with loneliness scores of 4.4 and 4.8, respectively), and among Turks ( 0.8 points, with loneliness 


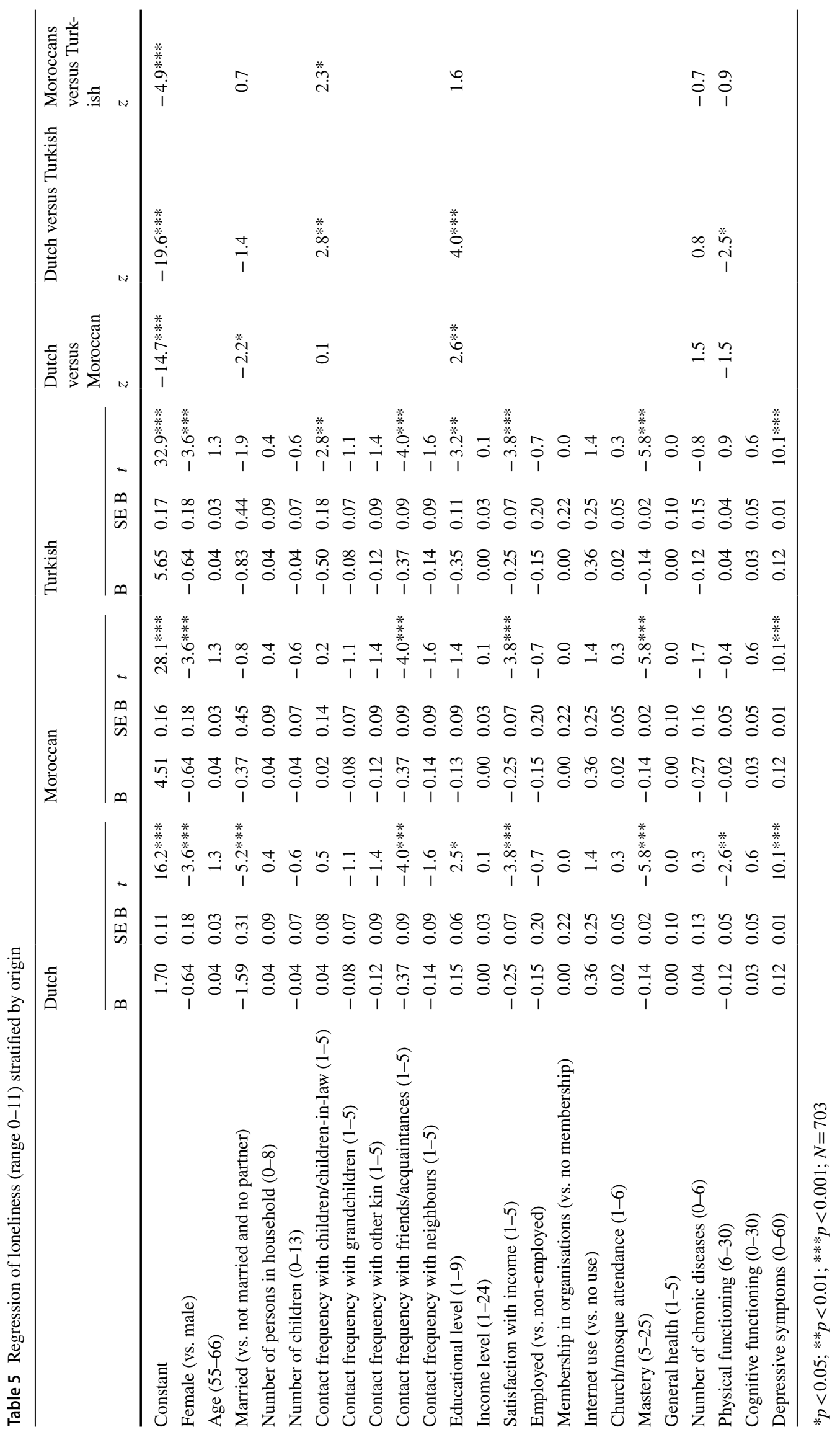


scores of 5.5 and 6.3, respectively). A higher contact frequency with children and children-in-law protects Turks, but not Moroccans or Dutch. For Turks without children or less than monthly contact with their children/children-in-law, which applies to $7 \%$ of Turks only, the estimated loneliness score is 7.3 and for everyday contact (46\% of Turks) it is 5.3. The estimates for Dutch and Moroccans hardly vary with contact frequency. A higher educational level protects Moroccans ( 0.8 points lower in loneliness score; not significant) and Turks (2.1 points lower); Dutch with a higher educational level score 0.9 more points in loneliness than Dutch with a lower educational level. Better physical functioning protects the Dutch (a 1.1-point advantage compared to those with poor physical functioning) better than Turks (a non-significant 0.3-point disadvantage); Moroccans with a high level of physical functioning have a non-significant advantage of 0.2 points.

\section{Discussion}

Older migrants of Moroccan origin and in particular of Turkish origin are on average lonelier than their Dutch age peers. This has already been observed in the four big Dutch cities (el Fakiri and Bouwman-Notenboom 2015; Uysal-Bozkir et al. 2017), and the results of this research in fifteen cities confirm it. The now-established psychometric characteristics of the loneliness scale of De Jong Gierveld denote that the scale within each origin category is very useful. The test of concurrent validity indicates that the loneliness scale has a good resemblance with direct measurements of loneliness. For comparison between the categories, it is important that the item characteristic curves in the three origin categories be approximately the same. For six items, the similarity was statistically insufficient. This large number is inseparable from sample size and should therefore not be taken as starting point for an assessment. In qualitative research (Torensma 2014), one of these six items and another item were described as interculturally sensitive. The item about pleasure of social company ('conviviality'), where we found the biggest problem, was not found to be problematic in that study. Hence, there are clear signs that some items have different weights for the three origin categories, and further research is desirable. But because the scale consists of different items, item-specific biases may compensate each other in the sum score. Research into homogeneity, reliability, concurrent validity and bias currently provides sufficient indications of the validity of the scale as a whole and does not preclude research comparing intensity of loneliness between different categories of origin.

In the field of social relationships, older migrants are better protected than older Dutch adults, at least in terms of availability of and contact within relationships. No information was available on other aspects such as content of the relationships, which might explain why marriage appears to protect the Dutch more than Moroccans and why frequent contact with children and children-in-law is most protective for Turks. Previous research (Visser and el Fakiri 2016) did examine the significance for loneliness of a partner relationship and contact with neighbours, but not the significance of other types of social relationships. Another Dutch study (ten Kate et al. 2020) among middle-aged and older non-Western migrants from five different countries together showed that their lower relationship satisfaction compared to Dutch people was related to higher loneliness. Relationship satisfaction, however, is conceptually close to loneliness, and relationship content was not measured.

In line with the expectation, we found that Dutch older migrants are at a greater risk in the domains of socio-economic position, social participation, health and mastery, and that this is related to their average stronger loneliness. Moreover, older migrants experience more severe consequences from a lower educational level (Moroccans and Turks) and poorer physical functioning (Turks) than non-migrants. For the first three domains, this corresponds with the results of earlier Dutch research among migrants (Visser and el Fakiri 2016). These four domains also appeared to be important in research into ageing among older Dutch adults, but only from the age of 70 (van Tilburg et al. 2018). The comparison of older Moroccans and Turks aged around 60 with their Dutch age peers, 'young-olds', is less appropriate.

We only examined risk factors for which data were available in both data sets. The LASA study among older Dutch adults was not designed for comparison with migrants. For example, poor Dutch language proficiency may pose a risk of loneliness for migrants (Klok et al. 2017), but it is unknown whether language proficiency is a factor in the development or persistence of loneliness among respondents of Dutch origin. Migrant-specific factors cannot be included in the comparison with the Dutch. For example, transnational behaviour increases the risk of loneliness (Klok et al. 2017). Because migrants want to keep their own identity and culture, they are focused on their home country next to their life in the Netherlands. For a long time, their social life in the Netherlands was not a priority because there was a prospect of return. Factors such as social exclusion, discrimination and insufficient accessibility to regular professional care have not been investigated. Neither could we pay any attention to differences between the categories of origin with respect to their views on the priority they give to their individual goals versus those of the collective they are part of. Dutch culture was already highly individualistic decades ago compared to Morocco and Turkey (Hofstede 1983), and this may mean that older Dutch adults have different expectations and are less likely to feel lonely than older Moroccans and Turks (Swader 2019). The present study therefore gives a 
very limited view on cross-cultural factors in loneliness and has a limited view on the diversity within the three origin categories.

The increased vulnerability of migrants ensues from a combination of three circumstances: they have experienced the stressful event of having left their home country and are growing old in a second homeland where they are a minority (Dowd and Bengtson 1978). Migration caused a cultural shock (Oberg 1960), as they were confronted with behaviours, customs, beliefs and a food culture, landscape, climate and language that were different. Adaptation and alignment are stressful (Berry et al. 1987), and stress increases the risk of loneliness. Migrants are a disadvantaged minority that is treated as such. In the Netherlands, there are many negative prejudices against Moroccan and Turkish migrants (Coenders et al. 2015; Pettigrew et al. 1997). In addition to the factors investigated that provide important explanations for the differences in loneliness between migrants and older Dutch adults, personal migration history and experiences of deprivation and ethnic discrimination could also plausibly contribute to their loneliness.

We suggest that practitioners, in particular those who develop and execute loneliness interventions, may profit from the results. Many loneliness interventions focus on increasing the possibilities for meeting other people, personal contact and practical support (Gardiner et al. 2018). This choice can be followed from the definition of loneliness where the lack of personal relationships is central. From the results of this research, it is clear that this type of intervention does not sufficiently address the loneliness problem of many older migrants. Several factors have proven to be important in other domains, namely weak socio-economic position, low level of social participation, lack of mastery and copious depressive symptoms. This is indicative of the need to explore additional solutions. Examples include focusing on meaningful activities, strengthening the experience of having a socially valued role, and avoiding negative interpretations.

We found that many but not all protective effects of loneliness-associated characteristics are universal across the three categories. For example, many Turks have frequent contact with children and children-in-law, but for those who have none, improving contact frequency may be beneficial. The similarity in risk factors among older Dutch and older migrants suggests that an approach which is potentially effective among older adults of Dutch origin can also be applied to older migrants. Such an intervention approach may need to be adapted to migrants in order to be successful. It is also necessary to determine which migrant-specific factors need to be taken into account in the approach.

Acknowledgement The Longitudinal Aging Study Amsterdam (https ://doi.org/10.17026/dans-287-pkwn) is supported by a grant from the
Netherlands Ministry of Health, Welfare and Sports, Directorate of Long-Term Care. The data collection was financially supported by a grant awarded to the first author by the Netherlands Organization for Scientific Research (NWO) in the context of the project 'New Cohorts of young old in the 21 st century' (file number 480-10-014).

Open Access This article is licensed under a Creative Commons Attribution 4.0 International License, which permits use, sharing, adaptation, distribution and reproduction in any medium or format, as long as you give appropriate credit to the original author(s) and the source, provide a link to the Creative Commons licence, and indicate if changes were made. The images or other third party material in this article are included in the article's Creative Commons licence, unless indicated otherwise in a credit line to the material. If material is not included in the article's Creative Commons licence and your intended use is not permitted by statutory regulation or exceeds the permitted use, you will need to obtain permission directly from the copyright holder. To view a copy of this licence, visit http://creativecommons.org/licenses/by/4.0/.

\section{References}

Ajrouch KJ (2008) Social isolation and loneliness among Arab American elders: cultural, social, and personal factors. Res Hum Dev 5:44-59. https://doi.org/10.1080/15427600701853798

Baumeister RF, Leary MR (1995) The need to belong: desire for interpersonal attachments as a fundamental human motivation. Psychol Bull 117:497-529. https://doi.org/10.1037/0033-2909.117.3.497

Bendermacher N (2010) Beyond alpha: lower bounds for the reliability of tests. J Mod Appl Stat Methods 9:95-102. https://doi. org/10.22237/jmasm/1272687000

Berry JW, Kim U, Minde T, Mok D (1987) Comparative studies of acculturative stress The. Int Migrat Rev 21:491-511. https://doi. org/10.2307/2546607

Bound Alberti F (2018) This "modern epidemic": Loneliness as an emotion cluster and a neglected subject in the history of emotions. Emot Rev 10:242-254. https://doi.org/10.1177/1754073918 768876

Clogg CC, Petkova E, Haritou A (1995) Statistical methods for comparing regression coefficients between models. Am J Sociol 100:1261-1293. https://doi.org/10.1086/230638

Coenders M, Lubbers M, te Grotenhuis M, Thijs P, Scheepers P (2015) Trends in etnocentrische reacties onder de Nederlandse bevolking, 1979-2012 [Trends in ethnocentric reactions among the Dutch population, 1979-2012]. Mens en Maatschappij 90:405-433. https ://doi.org/10.5117/mem2015.3.coen

Conkova N, Lindenberg J (2018) Gezondheid en welbevinden van oudere migranten in Nederland: Een narratieve literatuurstudie [Health and wellbeing of older migrants in the Netherlands: a narrative literature review]. Tijdschrift voor Gerontologie en Geriatrie 49:223-231. https://doi.org/10.1007/s12439-018-0268-2

de Groot AD (1961) Methodologie: Grondslagen van onderzoek en denken in de gedragswetenschappen [Methodology: Foundations of research and thinking in behavioural sciences]. Van Gorcum, Assen

de Jong Gierveld J, van Tilburg TG (1999) Manual of the loneliness scale. Vrije Universiteit, Department of Social Research Methodology, Amsterdam

de Jong Gierveld J, van Tilburg TG (2010) The De Jong Gierveld short scales for emotional and social loneliness: tested on data from 7 countries in the UN generations and gender surveys. Eur J Ageing 7:121-130. https://doi.org/10.1007/s10433-010-0144-6 
de Jong Gierveld J, Keating N, Fast JE (2015) Determinants of loneliness among older adults in Canada Canadian. Journal on Aging/ La Revue Canadienne du Vieillissement 34:125-136. https://doi. org/10.1017/S0714980815000070

de Jong Gierveld J, van Tilburg TG, Dykstra PA (2018) New ways of theorizing and conducting research in the field of loneliness and social isolation. In: Vangelisti AL, Perlman D (eds) The Cambridge handbook of personal relationships. Cambridge University Press, Cambridge, pp 391-404. https://doi.org/10.1017/97813 16417867.031

de Tavernier W, Draulans V (2019) Negotiating informal elder care, migration and exclusion: the case of a Turkish immigrant community in Belgium. Int J Ageing Later Life 12:89-117. https://doi. org/10.3384/ijal.1652-8670.18404

Dowd JJ, Bengtson VL (1978) Aging in minority populations: an examination of the double jeopardy hypothesis. J Gerontol 33:427-436. https://doi.org/10.1093/geronj/33.3.427

du Plooy DR, Lyons A, Kashima ES (2019) The effect of social support on psychological flourishing and distress among migrants in Australia. J Immigr Minor Health 21:278-289. https://doi. org/10.1007/s10903-018-0745-2

Durak M, Senol-Durak E (2010) Psychometric qualities of the UCLA Loneliness Scale-version 3 as applied in a Turkish culture. Educa Gerontol 36:988-1007. https://doi.org/10.1080/036012710037566 28

el Fakiri F, Bouwman-Notenboom J (2015) Gezondheid van oudere migranten in de vier grote steden [Health of older migrants in the four major cities]. GGD Amsterdam, Amsterdam

Fokkema T, Naderi R (2013) Differences in late-life loneliness: a comparison between Turkish and native-born older adults in Germany. Eur J Ageing 10:289-300. https://doi.org/10.1007/s1043 3-013-0267-7

Fokkema T, de Jong Gierveld J, Dykstra PA (2012) Cross-national differences in older adult loneliness. J Psychol 146:201-228. https:// doi.org/10.1080/00223980.2011.631612

Folstein MF, Folstein SE, McHugh PR (1975) 'Mini-Mental State': a practical method for grading the cognitive state of patients for the clinician. J Psychiatr Res 12:189-198. https://doi. org/10.1016/0022-3956(75)90026-6

Gardiner C, Geldenhuys G, Gott M (2018) Interventions to reduce social isolation and loneliness among older people: an integrative review. Health Soc Care Community 26:147-157. https://doi. org $/ 10.1111 / \mathrm{hsc} .12367$

Hansen T, Slagsvold B, Moum T (2009) Childlessness and psychological well-being in midlife and old age: an examination of parental status effects across a range of outcomes. Soc Indic Res 94:343362. https://doi.org/10.1007/s11205-008-9426-1

Hawkley LC, Gu Y, Luo YJ, Cacioppo JT (2012) The mental representation of social connections: generalizability extended to Beijing adults. PLoS ONE 7:e44065. https://doi.org/10.1371/journ al.pone. 0044065

Hofstede G (1983) The cultural relativity of organizational practices and theories. J Int Bus Stud 14:75-89. https://doi.org/10.1057/ palgrave.jibs. 8490867

Hu LT, Bentler PM (1999) Cutoff criteria for fit indices in covariance structure analysis: conventional criteria versus new alternatives. Struct Equ Model 6:1-55. https://doi.org/10.1080/1070551990 9540118

Huisman M, Poppelaars J, van der Horst M, Beekman AT, Brug J, van Tilburg TG, Deeg DJ (2011) Cohort profile: the Longitudinal Aging Study Amsterdam. Int J Epidemiol 40:868-876. https://doi. org/10.1093/ije/dyq219

Klok J, van Tilburg TG, Suanet BA, Fokkema T, Huisman M (2017) National and transnational belonging among Turkish and Moroccan older migrants in the Netherlands: protective against loneliness? Eur J Ageing 14:341-351. https://doi.org/10.1007/ s10433-017-0420-9

Leung K, Bond MH (1989) On the empirical identification of dimensions for cross-cultural comparisons. J Cross Cult Psychol 20:133-151. https://doi.org/10.1177/0022022189202002

Meyer IH (2003) Prejudice, social stress, and mental health in lesbian, gay, and bisexual populations: conceptual issues and research evidence. Psychol Bull 129:674-697. https://doi. org/10.1037/0033-2909.129.5.674

Mokken RJ (1971) A theory and procedure of scaling: with applications in political research. Mouton, Den Haag

Muthén LK, Muthen B (2017) Mplus user's guide: statistical analysis with latent variables. Muthén \& Muthén, Los Angeles

Nunnally JC, Bernstein IH (1994) Psychometric theory. McGraw-Hill, New York

Oberg K (1960) Cultural shock: adjustment to new cultural environments. Practical Anthropol 7:177-182. https://doi. org/10.1177/009182966000700405

Osterlind SJ, Everson HT (2009) Differential item functioning. Sage, London

Pearlin LI, Schooler C (1978) The structure of coping. J Health Soc Behav 19:2-21. https://doi.org/10.2307/2136319

Perlman D (2004) European and Canadian studies of loneliness among seniors. Canadian Journal on Aging-Revue Canadienne du Vieillissement 23:181-188. https://doi.org/10.1353/ cja.2004.0025

Pettigrew TF, Jackson JS, Brika JB, Lemaine G, Meertens RW, Wagner U, Zick A (1997) Outgroup prejudice in Western Europe. Eur Rev Soc Psychol 8:241-273. https://doi.org/10.1080/14792 779843000009

Radloff LS (1977) The CES-D scale: a self-report depression scale for research in the general population. Appl Psychol Meas 1:385-401. https://doi.org/10.1177/014662167700100306

Schellingerhout R (2004) Gezondheid en welbevinden van allochtone ouderen [Health and well-being of elderly people of foreign origin]. Sociaal en Cultureel Planbureau, Den Haag

Spijker J, van der Wurff FB, Poort EC, Smits CHM, Verhoeff AP, Beekman ATF (2004) Depression in first generation labour migrants in Western Europe: the utility of the Center for Epidemiologic Studies Depression Scale (CES-D). Int J Geriatr Psychiatry 19:538-544. https://doi.org/10.1002/gps.1122

Steinbach A (2018) Older migrants in Germany. J Popul Ageing 11:285-306. https://doi.org/10.1007/s12062-017-9183-5

Swader CS (2019) Loneliness in Europe: personal and societal individualism-collectivism and their connection to social isolation. Soc Forces 97:1307-1336. https://doi.org/10.1093/sf/soy088

ten Kate RLF, Bilecen B, Steverink N (2020) A closer look at loneliness: why do first-generation migrants feel more lonely than their native Dutch counterparts? Gerontologist. https://doi. org/10.1093/geront/gnz192

Tesser PTM, van Dugteren FA, Merens JGF (1998) Rapportage minderheden 1998: de eerste generatie in de derde levensfase [Minority Report 1998: the first generation in the third stage of life]. Sociaal en Cultureel Planbureau, Rijswijk

Torensma M (2014) Wij zijn niet alleen: Een onderzoek naar verklaringen voor eenzaamheid onder Turkse Amsterdammers [We are not alone: An investigation into explanations for loneliness among Turkish Amsterdam citizens]. Universiteit van Amsterdam, thesis MSc Medical Anthropology and Sociology

Uysal-Bozkir Ö, Fokkema T, MacNeil-Vroomen JL, van Tilburg TG, de Rooij SE (2017) Translation and validation of the De Jong Gierveld loneliness scale among older migrants living in the Netherlands. J Gerontol Series B Psychol Sci Soc Sci 72:109_ 119. https://doi.org/10.1093/geronb/gbv044

van Tilburg TG, Havens B, de Jong Gierveld J (2004) Loneliness among older adults in the Netherlands, Italy, and Canada: a 
multifaceted comparison. Can J Aging 23:169-180. https://doi. org/10.1353/cja.2004.0026

van Tilburg TG, Iedema J, Klok J (2018) Veranderingen in eenzaamheid in de tweede levenshelft [Changes in loneliness in the second half of life]. In: van Campen C, Vonk F, van Tilburg TG (eds) Kwetsbaar en eenzaam? Risico's en bescherming in de ouder wordende bevolking. Sociaal en Cultureel Planbureau, Den Haag, pp 46-53

Vancluysen K, Van Craen M (2011) Feelings of loneliness: differences between ethnic minority and majority group members in Belgium and their relation to minorities' integration and ethnic attachment. In: Motmans J, Cuypers D, Meier P, Mortelmans D, Zanoni $\mathrm{P}$ (eds) Equal is not enough: challenging differences and inequalities in contemporary society. Policy Research Centre on Equal Opportunities, Antwerp, pp 436-449
Victor CR, Burholt V, Martin W (2012) Loneliness and ethnic minority elders in Great Britain: an exploratory study. J Cross Cult Gerontol 27:65-78. https://doi.org/10.1007/s10823-012-9161-6

Visser MA, el Fakiri F (2016) The prevalence and impact of risk factors for ethnic differences in loneliness. Eur J Public Health 26:977983. https://doi.org/10.1093/eurpub/ckw115

Wu Z, Penning MJ (2015) Immigration and loneliness in later life. Ageing Soc 35:64-95. https://doi.org/10.1017/S0144686X13000470

Publisher's Note Springer Nature remains neutral with regard to jurisdictional claims in published maps and institutional affiliations. 